Revista Destaques Acadêmicos, Lajeado, v. 12, n. 4, 2020. ISSN 2176-3070

DOI: http://dx.doi.org/10.22410/issn.2176-3070.v12i4a2020.2411

http://www.univates.br/revistas

\title{
ANÁLISE DA INFLUÊNCIA DE MATERIAIS E MÉTODOS CONSTRUTIVOS NO DESEMPENHO TÉRMICO EM HABITAÇÃO SOCIAL NO MUNICÍPIO DE LAJEADO/RS
}

\author{
Alfredo Henrique Giovanaz ${ }^{1}$, Isabel Kristiner ${ }^{2}$, João Marcos Sartori ${ }^{3}$
}

Resumo: O desempenho térmico das edificações impacta diretamente no conforto do usuário no decorrer das suas atividades diárias e auxilia na manutenção do consumo de energia. O presente trabalho tem por objetivo analisar a influência dos materiais e métodos construtivos no desempenho térmico em apartamentos de um condomínio de habitação e interesse social projetado no município de Lajeado/RS e expor soluções buscando a redução da carga térmica da edificação. Para tal, as recomendações descritas no presente trabalho alteram os materiais recomendados em projeto, reduzindo assim as demandas de climatizadores artificiais. Para coleta de dados, foram avaliados os ambientes de permanência prolongada (dormitórios e sala de estar), analisando a carga térmica oriunda das paredes, cobertura, equipamentos eletrônicos e número de pessoas ocupantes, conforme a NBR 15575 (ABNT, 2013). Realizou-se então três modificações significativas nas especificações do projeto original, sendo elas: adição de placa de EPS com espessura de $3 \mathrm{~cm}$ sobre a laje de cobertura, substituição da telha metálica para telha pré pintada na cor branca e troca da cor da tinta da fachada para a cor marifm. Com isto, verificou-se uma redução de até $43 \%$ na carga térmica dos apartamentos, reduzindo o custo com aparelhos de ar condicionado em até $41 \%$ nos casos estudados.

Palavra-chave: Desempenho térmico. Conforto. Ar condicionado.

\section{INTRODUÇÃO}

O desempenho energético das edificações residenciais está condicionado a diversos fatores que influenciam no seu comportamento, tais como: traços arquitetônicos do edifício, propriedades físicas dos materiais utilizados,

1 Bacharel em Engenharia Civil pela Universidade do Vale do Taquari - UNIVATES. ahgiovanaz@universo.univates.br

2 Acadêmica em Engenharia Civil pela Universidade do Vale do Taquari - UNIVATES. isabel.kristiner@universo.univates.br

3 Bacharel em Engenharia Civil pela Universidade do Vale do Taquari - UNIVATES. joaomarcos@universo.univates.br 
orientação solar dos ambientes, equipamentos instalados, iluminação, sistema de ventilação e condicionamento artificial, métodos de bloqueio da luz solar e características climáticas. Além destes, há ainda a atuação do comportamento do usuário no desempenho térmico e energético, por meio de interações com sistemas de iluminação, ventilação, condicionamento artificial, aberturas e sombreamentos de janelas (SORGATO, 2015).

A NBR 15575 (ABNT, 2013) trata do desempenho das edificações habitacionais e mostra os requisitos e características fundamentais para uma obra apresentar resultados positivos quanto ao conforto, acessibilidade, higiene, estabilidade, vida útil da construção, segurança estrutural e incêndios. O desempenho térmico impacta diretamente no conforto do usuário no decorrer das suas atividades diárias e auxilia para a redução dos gastos de energia. A referida norma não se dedica em obter conforto térmico por meio de climatizadores artificiais (refrigeração e calefação), mas sim, está voltada ao desempenho das edificações em condições naturais de radiação solar, ventilação e outros quesitos.

Conforme Meira (2018), o tema sustentabilidade nas cidades tem gerado inúmeras pesquisas visando conforto térmico das edificações por meio de alterações das técnicas construtivas, utilizando materiais que servem como controladores da temperatura interna do ambiente, visando uma eficiência maior do sistema, principalmente em regiões onde há inverno e verão com temperaturas bem definidas, fazendo uma avaliação das demandas de trocas térmicas nos ambientes.

Tendo em vista o contexto apresentado, o presente estudo tem como objetivo principal analisar a influência dos materiais e métodos construtivos no desempenho térmico em apartamentos de um condomínio de habitação e interesse social projetado no município de Lajeado/RS e expor soluções buscando a redução da carga térmica da edificação. Os ambientes levantados são considerados de permanência prolongada, sendo estes dormitórios e sala de estar/cozinha. Os objetivos específicos contemplam a análise da orientação solar dos apartamentos em relação à carga térmica e comparação na redução da potência necessária nos climatizadores artificiais e impactos na redução do custo de energia elétrica para o usuário.

Sabe-se que os edifícios estão constantemente expostos às variações climáticas e estas influenciam diretamente nas condições térmicas internas de cada edificação. Em dias de sol, a incidência de luz aquece o conjunto de materiais que constituem a edificação (fenômeno percebido mais facilmente no verão). Por outro lado, no inverno observa-se o oposto, com o resfriamento do prédio, causado devido às massas de ar polar incidentes sobre a construção. Desta forma os ambientes estão constantemente ganhando ou perdendo calor, uma vez que a natureza busca sempre o equilíbrio térmico e isso inclui o comportamento dos materiais (FOGIATTO, 2015). 
As trocas de calor podem apresentar-se de três formas: por condução, por convecção e por irradiação. De maneira simplificada, a condução acontece quando dois corpos estão em contato. A convecção ocorre com a movimentação das massas de ar. E por fim, a irradiação com a incidência direta de energia, como por exemplo, a irradiação solar incidindo sobre um material e gerando o aquecimento do mesmo (OLIVEIRA, 2015).

Roriz (2008) explica que material reage de forma única quando exposto a uma perda ou um ganho de energia devido a seu comportamento característico. Numa analogia geral, um mesmo material possui diversos aspectos os quais devemos considerar quando se trata de desempenho térmico. Dentro destas especificidades, algumas estão passíveis de alteração, como a coloração e reflexão do material. No entanto, temos também, algumas propriedades que são inalteráveis, como por exemplo, a condutividade.

Na construção civil, geralmente são empregados um conjunto de materiais com características diferentes, como por exemplo a alvenaria que é a união dos materiais cerâmicos com os cimentícios. Deste modo, tem se variações de condutividade que impactaram diretamente na transmitância térmica da alvenaria, que por sua vez impacta diretamente na carga térmica das edificações.

\section{METODOLOGIA}

O presente trabalho utiliza o estudo de caso como procedimento de desenvolvimento de sua pesquisa. Este método oportuniza o estudo detalhado de poucos objetos que compõem um determinado problema durante um período de tempo limitado, promovendo o conhecimento amplo e detalhado do mesmo (VENTURA, 2007; GIL, 2008).

$\mathrm{O}$ estudo em questão tem como base um projeto de condomínio de habitação e interesse social localizado na cidade de Lajeado/RS, configurando Zona Bioclimática 2 conforme NBR 15220-3 (ABNT, 2005). As unidades a serem analisadas estão distribuídas em dois blocos do conjunto habitacional, dispostas conforme planta de localização na Figura 1. Os apartamentos denominados a partir deste momento de $1 \mathrm{~A}$ e $1 \mathrm{~B}$ possuem planta baixa com layout idêntico, dois dormitórios e fachada principal na orientação leste/oeste, enquanto que as unidades $2 \mathrm{~A}$ e $2 \mathrm{~B}$ também apresentam planta baixa de mesmas características, com um dormitório, e fachadas principais dispostas na orientação norte/sul. As quatro unidades localizam-se no último pavimento do bloco residencial, possuindo laje de cobertura e telhado. 
Figura 1 - Planta baixa de localização.

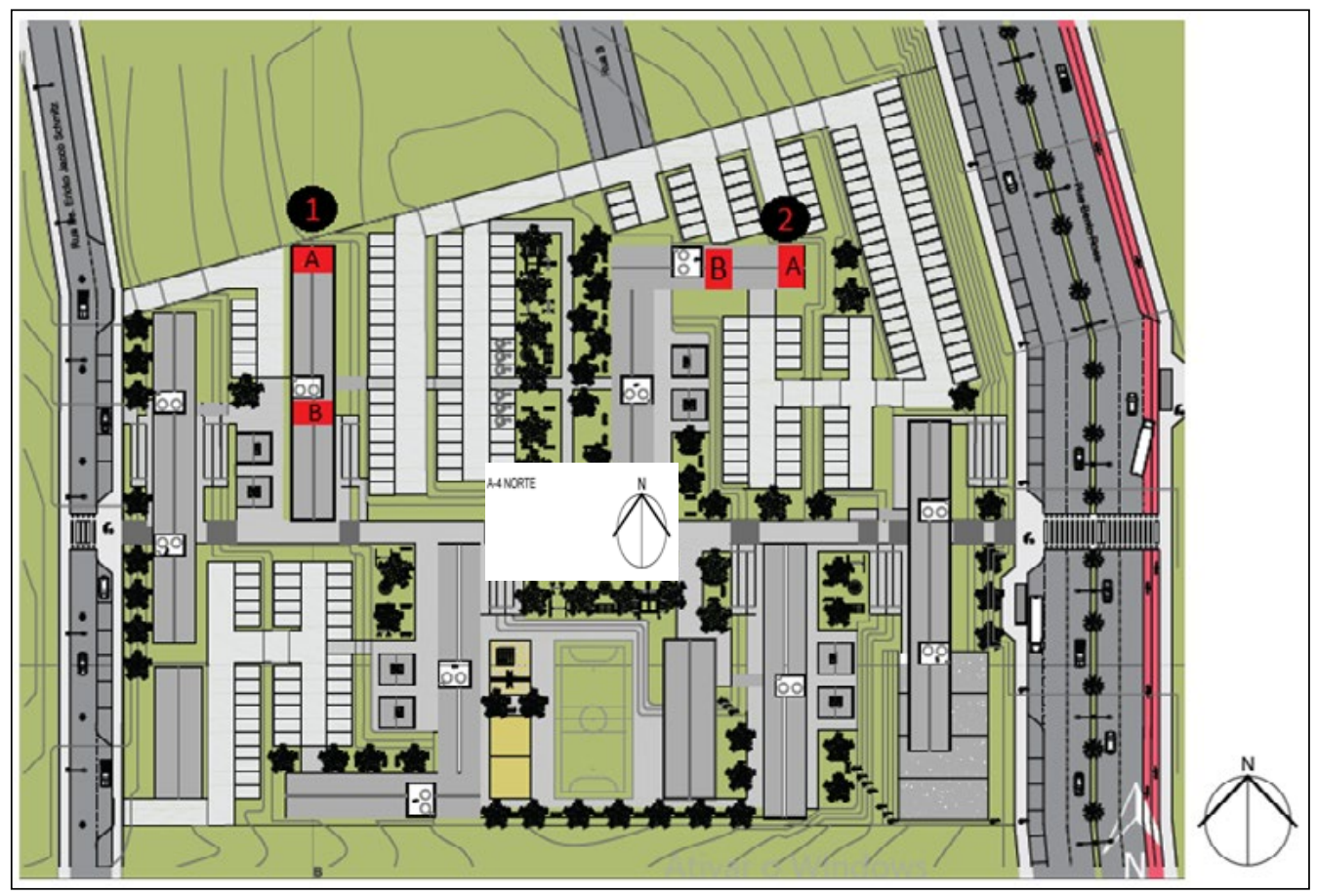

Fonte: Dos autores (2019).

A análise de dados e dimensionamento de ar condicionado aconteceram por meio de determinação da carga térmica dos ambientes de permanência prolongada, tais como sala e cozinha conjugada e dormitórios, dos quatro apartamentos mencionados no estudo. Adotou-se as unidades $1 \mathrm{~A}$ e $2 \mathrm{~A}$ como representantes da situação mais crítica de conforto térmico por se localizarem na extremidade do pavimento (FIGURA 2). 
Figura 2 - Planta baixa apartamentos 1A e 2A.

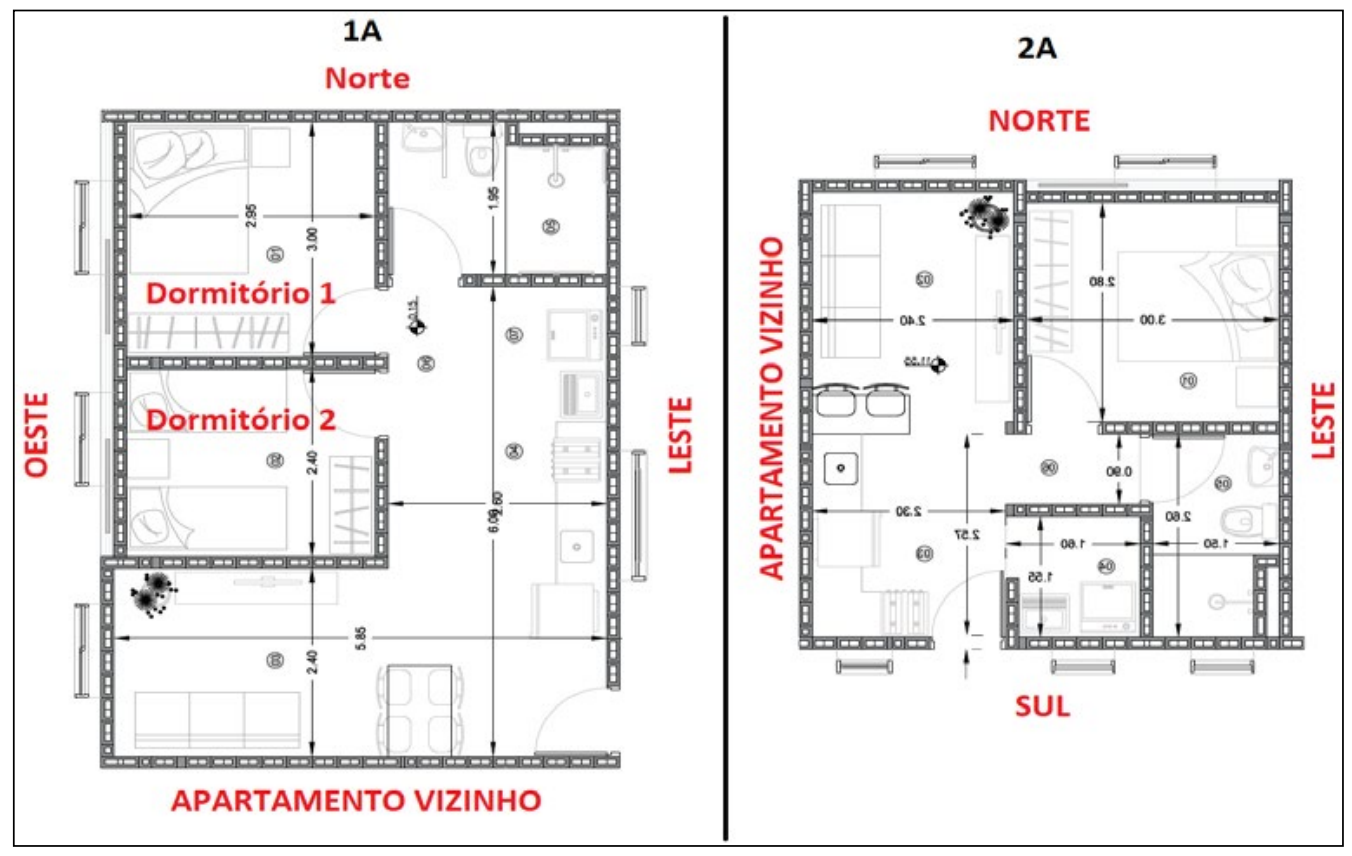

Fonte: Autores (2019).

A parcela de carga térmica proveniente das paredes, esquadrias e coberturas foi mensurada através do fluxo térmico dos sistemas, este está relacionado com a transmitância térmica dos materiais. Todos os apartamentos analisados nas simulações localizam-se no último pavimento de cada edifício. A laje de cobertura é do tipo maciça de $12 \mathrm{~cm}$ de espessura, com telhado em telha fibrocimento, espessura de $8 \mathrm{~mm}$, classificado como muito ventilado. Não foi considerado rebaixo em forro sob a laje.

As paredes de alvenaria estrutural foram consideradas em bloco de concreto nas dimensões $19 \mathrm{~cm} \times 19 \mathrm{~cm} \times 39 \mathrm{~cm}$ (com parede de $3 \mathrm{~cm}$ ), com revestimento em reboco de espessura $2,5 \mathrm{~cm}$ em cada face e junta de argamassa de espessura $1 \mathrm{~cm}$. A pintura externa é a na cor cinza, em todas as fachadas. Nas esquadrias dos dormitórios foi considerado um brise de madeira em frente à janela com vidro temperado de $6 \mathrm{~mm}$. A esquadria da sala possui vidro de espessura $8 \mathrm{~mm}$ e nenhuma barreira externa. $\mathrm{O}$ acesso aos apartamentos é por corredor aberto, com guarda corpo em PVC e coberto com marquise, sendo assim, deve-se considerar o fator marquise nesta fachada. A Figura 3 representa as fachadas principais do bloco de apartamentos de dois dormitórios. 
Figura 3-Fachada com brise e fachada com marquise.

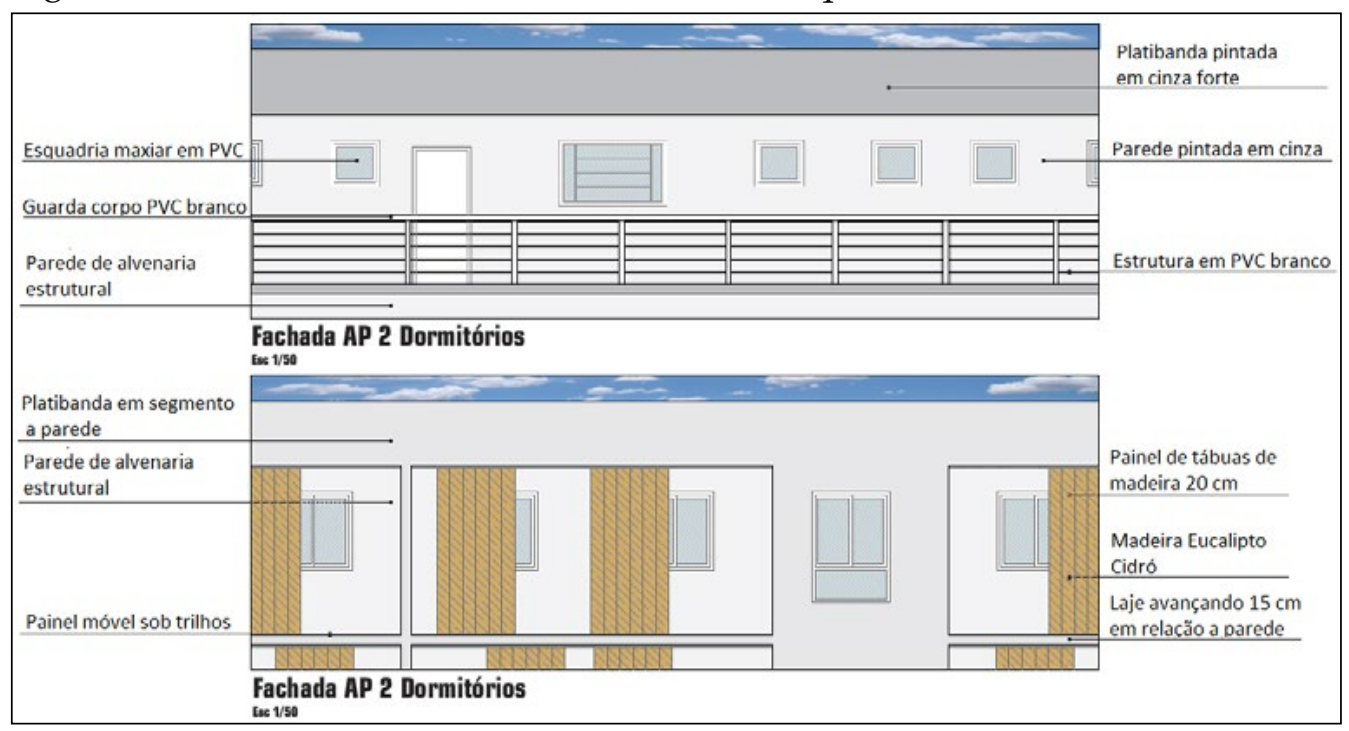

Fonte: Dessoy (2017).

Além dos sistemas e materiais construtivos mencionados, a carga térmica também contempla o ganho de calor por ocupantes na edificação, onde considerou-se $150 \mathrm{~W}$ por ocupante, sendo contabilizados quatro ocupantes para os apartamentos de dois dormitórios (1A e 1B), e dois para os apartamentos de apenas um dormitório ( $2 \mathrm{~A}$ e $2 \mathrm{~B}$ ). $\mathrm{O}$ ganho de calor proveniente da iluminação artificial foi contemplado atribuindo $18 \mathrm{~W}$ para cada ponto de luminária existente. A influência dos eletrodomésticos e demais equipamentos foi mensurada em $410 \mathrm{~W}$, a serem adicionados no ambiente da sala de estar e cozinha conjugadas. O diagrama representado na Figura 4 esquematiza as fases do presente estudo. 
Figura 4-Diagrama das etapas de execução da metodologia científica.

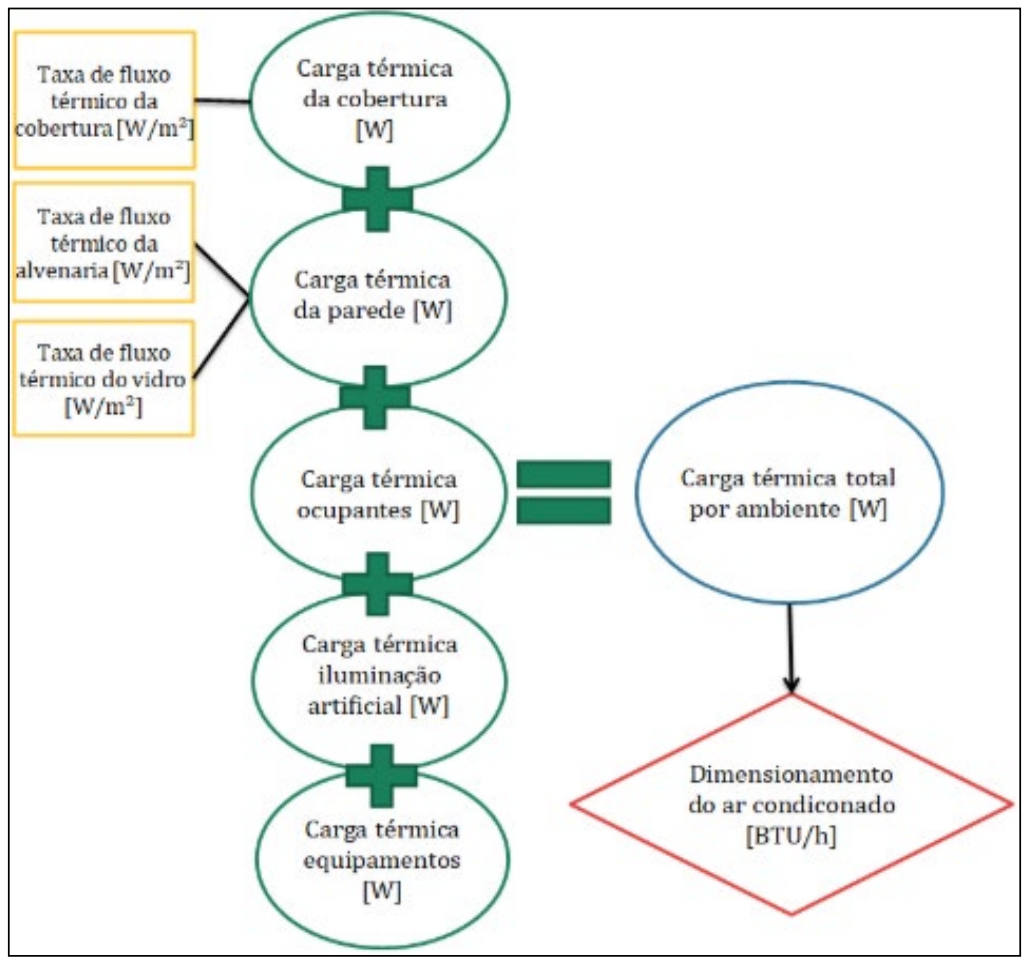

Fonte: Dos autores (2019)

Após o dimensionamento do equipamento de ar condicionado nos quatro apartamentos analisados, foram propostas modificações construtivas a fim de melhorar o conforto térmico em cada unidade e, consequentemente, reduzir a demanda dos aparelhos climatizadores. As alterações propostas nos materiais inicialmente descritos são: adição de placas de EPS com espessura $3 \mathrm{~cm}$ sobre a laje de cobertura; substituição da telha para telha metálica com espessura de $0,65 \mathrm{~cm}$ pré pintada em branco; e, troca da cor da tinta para cor marfim.

A partir das melhorias propostas, as etapas descritas na Figura 4 foram recalculadas, determinando a nova carga térmica em todos os cômodos dos apartamentos verificados. Por fim, os resultados obtidos nas novas simulações serão comparados com o projeto original, permitindo concluir o impacto de cada alteração adotada.

\section{RESULTADOS E DISCUSSÃO}

Neste capítulo serão apresentados e analisados os dados resultantes das simulações e comparações realizadas. 


\subsection{Carga térmica da cobertura}

A influência proveniente da cobertura foi o primeiro parâmetro a ser analisado, a taxa de fluxo térmico foi utilizada em todas as unidades, independente da orientação solar. Para o cálculo do fluxo térmico da cobertura adotou-se o índice de radiação solar de topo $(\mathrm{H})$, no horário do meio dia para a data de 22 de dezembro de acordo com tabela de radiação solar incidente sobre planos verticais e horizontais (Gonçalves, 1955).

A Tabela 1 compara os valores de transmitância térmica e taxa de fluxo de calor considerando o (1) projeto original: laje maciça de concreto e telha em fibrocimento; (2) a primeira alteração proposta, inclusão de camada de EPS de $3 \mathrm{~cm}$ imediatamente sobre a laje e mantendo a telha original; (3) a segunda alteração proposta, mantendo apenas a laje maciça e alterando a telha para metálica pré pintada em branco; e, por fim, (4) a junção das duas alterações.

Tabela 1-Diagrama das etapas de execução da metodologia científica.

\begin{tabular}{lccc}
\hline & $\mathbf{U}\left[\left(\mathbf{m}^{2} \cdot \mathbf{K}\right) / \mathrm{W}\right]$ & $\mathbf{q}_{\mathrm{fo}}\left[\mathbf{W} \cdot \mathbf{m}^{2}\right]$ & $\begin{array}{c}\text { \% de redução } \\
\text { fluxo térmico }\end{array}$ \\
\hline (1) Projeto original & 1,996 & 87,43 & \\
\hline (2) Inclusão de EPS e=3cm & 0,799 & 35,01 & $60 \%$ \\
\hline $\begin{array}{l}\text { (3) Substituição para telha } \\
\text { metálica branca }\end{array}$ & 2,047 & 35,14 & $60 \%$ \\
\hline (4) Uso de EPS e telha metálica & 0,807 & 13,86 & $84 \%$ \\
\hline
\end{tabular}

Fonte: Dos autores (2019).

Observa-se que com a alteração da telha de fibrocimento para a telha metálica houve um aumento de $61 \%$ na transmitância térmica em relação ao projeto original, isso ocorre devido ao alto valor de condutividade térmica da telha metálica. Apesar disso, a taxa de fluxo térmico reduziu $60 \%$ devido à considerável redução do índice de absorvidade da cor branca da telha em relação à cor cinza.

Assim, no desenvolvimento inicial da carga térmica do projeto original foi considerado o valor de taxa de fluxo térmico de $87,43 \mathrm{~W} / \mathrm{m}^{2}$ a ser utilizado em todos os ambientes. Para a simulação de melhorias, a taxa de fluxo térmico adotada é de $13,86 \mathrm{~W} / \mathrm{m}^{2}$.

\subsection{Carga térmica da parede}

Na determinação da carga térmica proveniente das paredes deve-se considerar a condução pelo fechamento opaco (alvenaria), condução pelas aberturas (esquadrias) e ganho solar pelo vidro. A transmitância térmica da 
parede em bloco de concreto resultou em 1,27 W/( $\left.\mathrm{m}^{2} . \mathrm{K}\right)$, estando de acordo com a NBR 15575-1 (ABNT, 2013) que limita o valor em $2,5 \mathrm{~W} /\left(\mathrm{m}^{2} . \mathrm{K}\right)$.

Como parte do cálculo de carga térmica para os apartamentos, foi determinado o fluxo térmico da parede em alvenaria para cada orientação de fachada. Constatou-se então que apenas com a variação de orientação da mesma, há uma diferença de $51 \%$ no valor do fluxo térmico, conforme dados apresentados na Tabela 2.

Tabela 2 - Fluxo térmico parede de alvenaria conforme orientação da fachada.

\begin{tabular}{ccccc}
\hline & $\begin{array}{c}\text { Fachada } \\
\text { Norte }\end{array}$ & Fachada Sul & $\begin{array}{c}\text { Fachada } \\
\text { Leste }\end{array}$ & Fachada Oeste \\
\hline $\begin{array}{c}\text { Fluxo térmico }\left(\mathrm{q}_{\mathrm{fo}}\right) \\
{\left[\mathrm{W} / \mathrm{m}^{2}\right]}\end{array}$ & 19,48 & 19,82 & 39,77 & 39,77 \\
\hline
\end{tabular}

Fonte: Dos autores (2019).

\subsection{Carga térmica por apartamentos}

Para fins de comparação, serão apresentados detalhadamente apenas os resultados obtidos nos apartamentos $1 \mathrm{~A}$ e $2 \mathrm{~A}$, que possuem fachadas em 3 orientações diferentes, e possuem carga térmica elevada dentro do seu bloco. Estes apresentaram as situações mais críticas devido à sua localização no pavimento.

\subsubsection{Apartamento 1A}

No apartamento 1A foram analisados três 3 cômodos: sala de estar/ cozinha, com orientação solar da fachada para leste/oeste; dormitório 1, com orientação para oeste, e; dormitório 2, com orientação solar para oeste/ norte. A Tabela 3 indica os valores obtidos em cada ambiente antes e depois das aplicações das melhorias. Nota-se uma maior diferença na sala de estar/ cozinha, pois com a utilização do projeto original seria necessário um arcondicionado de no mínimo 20.000 BTU's/h, e após a troca dos materiais utilizados, a demanda de carga térmica será atendida com uma máquina de 12.000 BTU's/h. Os ambientes de dormitórios tiveram uma redução da mesma proporção nos valores de carga térmica, no entanto, o climatizador a ser utilizado não alterou sua capacidade, visto que os valores estavam abaixo dos valores mínimos de máquinas encontradas no mercado. 
Tabela 3-Valores de carga térmica do apartamento 1A

\begin{tabular}{lcccc}
\hline & $\begin{array}{c}\text { Projeto } \\
\text { Original } \\
\text { (BTU's/h) }\end{array}$ & $\begin{array}{c}\text { Com } \\
\text { melhorias } \\
\text { (BTU's/h) }\end{array}$ & \% de redução & $\begin{array}{c}\text { Aparelho } \\
\text { Split } \\
\text { (BTU's/h) }\end{array}$ \\
\hline Sala de estar/cozinha & $18.958,62$ & $11.915,42$ & $37,15 \%$ & 12.000 \\
\hline Dormitório 1 & $5.453,33$ & $3.323,60$ & $39,05 \%$ & 7.000 \\
\hline Dormitório 2 & $6.183,11$ & $3.874,90$ & $37,33 \%$ & 7.000 \\
\hline Total & $30.595,06$ & $19.113,92$ & $37,33 \%$ & \\
\hline
\end{tabular}

Fonte: Dos autores (2019).

\subsubsection{Apartamento 2A}

Este apartamento possui apenas um dormitório, com orientação norte/ leste, que foi analisado juntamente com a sala de estar/cozinha, com orientação norte/sul. A Tabela 4 apresenta os valores encontrados no projeto original e após a aplicação das melhorias. Nota-se um percentual maior de redução da carga térmica geral do apartamento, quando comparado ao 1A. Isso ocorre devido às orientações das fachadas, que neste caso, possuem incidência solar predominante em Norte/Sul, enquanto o apartamento 1A possui mais fachadas nas orientações Leste/Oeste, que são as mais fortes e incidem maior carga aos ambientes.

Tabela 4-Valores de carga térmica do apartamento 2A

\begin{tabular}{lcccc}
\hline & $\begin{array}{c}\text { Projeto } \\
\text { Original } \\
\text { (BTU's/h) }\end{array}$ & $\begin{array}{c}\text { Com } \\
\text { melhorias } \\
\text { (BTU's/h) }\end{array}$ & \% de redução & $\begin{array}{c}\text { Aparelho } \\
\text { Split } \\
\text { (BTU's/h) }\end{array}$ \\
\hline Sala de estar/cozinha & 9.065 & 5.174 & $42,92 \%$ & 7.000 \\
\hline Dormitório 1 & 5.860 & 3.271 & $44,18 \%$ & 7.000 \\
\hline Total & 14.925 & 8.445 & $43,42 \%$ & \\
\hline
\end{tabular}

Fonte: Dos autores (2019).

\subsubsection{Análise global}

Analisando os ambientes de uma forma geral, pode-se visualizar o semelhante valor de redução nos apartamentos de mesmo bloco (1 e 2), o que deixa evidente a influência da orientação solar no desempenho térmico das edificações. A Tabela 5 a seguir apresenta os valores dos 4 apartamentos analisados. 
Tabela 5-Valores de carga térmica nos apartamentos

\begin{tabular}{lccc}
\hline & $\begin{array}{c}\text { Projeto Original } \\
\text { (BTU's/h) }\end{array}$ & $\begin{array}{c}\text { Com melhorias } \\
\text { (BTU's/h) }\end{array}$ & \% de redução \\
\hline Apartamento 1A & 30.595 & 19.114 & $37,53 \%$ \\
\hline Apartamento 1B & 30.079 & 18.697 & $37,84 \%$ \\
\hline Apartamento 2A & 14.925 & 8.445 & $43,42 \%$ \\
\hline Apartamento 2B & 13.926 & 7.819 & $43,85 \%$ \\
\hline
\end{tabular}

Fonte: Dos autores (2019).

Na Figura 5 pode-se verificar em um âmbito geral as reduções em todos apartamentos, comparadas em um gráfico para melhor expressão visual.

Figura 5 - Gráfico da análise global do desempenho das edificações

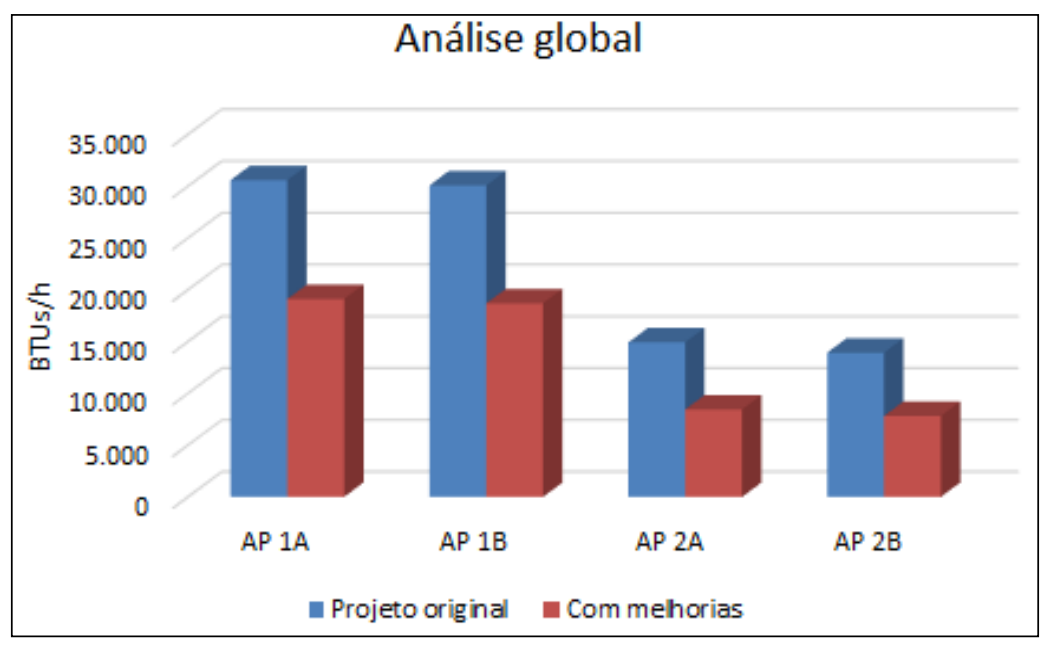

Fonte: Dos autores (2019).

\subsection{Redução de custos}

Com as alterações propostas no projeto original obteve-se reduções nas demandas de carga térmica nos ambientes. Consequentemente houve uma diminuição nos custos com climatização artificial. Considerando o valor do KW.h utilizado pela concessionária Certel de $\mathrm{R} \$ 0,61$, pode-se estimar os valores gastos com energia elétrica nos apartamentos analisados. $\mathrm{O}$ custo mensal considerando o ambiente da sala de estar e cozinha conjugada do apartamento $1 \mathrm{~A}$ foi reduzido em $41 \%$, enquanto o apartamento $2 \mathrm{~A}$ teve uma redução de $28 \%$ no mesmo ambiente. Essa menor redução no segundo caso se deve pelo fato de que a diferença de potência entre os equipamentos dimensionados tem menor 
impacto quando comparado ao apartamento 1A, que teve redução de 10.000 BTU's/h, contra apenas $2.000 \mathrm{BTU}$ 's / h do apartamento $2 \mathrm{~A}$.

Tabela 6 - Análise da redução dos custos

\begin{tabular}{lccccc}
\hline & $\begin{array}{c}\text { Split- Projeto } \\
\text { original } \\
\text { (BTU's/h) }\end{array}$ & $\begin{array}{c}\text { Custo } \\
\text { (R\$/mês) }\end{array}$ & $\begin{array}{c}\text { Split-pós } \\
\text { melhorias } \\
\text { (BTU's/h) }\end{array}$ & $\begin{array}{c}\text { Custo } \\
\text { (R\$/mês) }\end{array}$ & $\begin{array}{c}\text { \% redução } \\
\text { no custo }\end{array}$ \\
\hline $\begin{array}{l}\text { Apartamento 1A } \\
\begin{array}{l}\text { Sala/cozinha } \\
\text { (LESTE/OESTE) }\end{array}\end{array}$ & 22.000 & 355,00 & 12.000 & 207,00 & $41 \%$ \\
\hline $\begin{array}{l}\text { Apartamento 2a } \\
\begin{array}{l}\text { Sala/cozinha } \\
\text { (NORTE/SUL) }\end{array}\end{array}$ & 9.000 & 130,00 & 7.000 & 93,00 & $28 \%$ \\
\hline
\end{tabular}

Fonte: Autores (2019).

\section{CONCLUSÃO}

Com a proposta de três simples melhorias na escolha de matérias e sistema construtivo foi possível uma diminuição de até $43 \%$ na carga térmica do apartamento. O maior impacto da redução de carga causado pelas alterações propostas foi observado na unidade de fachada norte/sul.

Analisando as simulações de transmitância térmica e fluxo térmico apresentadas, fica a sugestão do uso de uma telha de fibrocimento de cor branca, somando a otimização da condutividade térmica do material e absorvidade proporcionada pela cor da superfície.

Além das três modificações desenvolvidas neste estudo, outros materiais e sistemas poderiam ser substituídos ou adicionados no projeto apresentado com o intuito de manter o conforto térmico, são eles: utilização de bloco cerâmico, instalação de brise na janela da sala e instalação de manta térmica no telhado.

\section{REFERÊNCIAS}

ASSOCIAÇÃO BRASILEIRA DE NORMAS TÉCNICAS. NBR 15220-3: Desempenho térmico de edificações Parte 3: Zoneamento bioclimático brasileiro e diretrizes construtivas para habitações unifamiliares de interesse social. Rio de Janeiro: ABNT, 2005.

2013.

. NBR 15575: Edificações Habitacionais - Desempenho. Rio de Janeiro: ABNT,

DESSOY, Felipe M. Condomínio de habitação e interesse social. Lajeado: Univates, 2017. 
FOGIATTO, Marcelo Antonio. Avaliação da Transmitância térmica de blocos cerâmicos e de concreto utilizados na construção civil. 2015. 51 f. TCC (Graduação) Curso de Engenharia Mecanica, Universidade Federal do Paraná, Ponta Grossa, 2015. Disponível em: <http:/ / repositorio.roca.utfpr.edu.br/jspui/bitstream/1/7515/1/ PG_DAMEC_2015_1_03.pdf>. Acesso em: 05 maio 2019.

GIL. Métodos e técnicas de pesquisa social. 6. ed. São Paulo: Atlas, 2008.

GONÇALVES, H. — O sol nos edifícios. Rio de Janeiro, Lemos, 1955.

MOBUSS CONSTRUÇÃO (Santa Catarina). Exigências de habitabilidade da NBR 15575 para edificações. 2018. Disponível em: <https:// www.mobussconstrucao.com. br/blog/habitabilidade-nbr-15575/\#comments>. Acesso em: 05 maio 2019.

OLIVEIRA, Raquel Diniz. Classificação do desempenho térmico da envoltória de habitação popular em concreto armado. 2015. 278 f. Monografia. (Pós-graduação)Curso de Engenharia Civil, Universidade Federal de Minas Gerais, Minas Gerais, 2015.

RORIZ, Mauricio. Conforto e desempenho térmico das edificações. 2008. $63 \mathrm{f}$. Monografia (Especialização) - Curso de Engenharia Civil, Universidade de Santa Maria, São Carlos, 2008. Disponível em: <http:/ /w3.ufsm.br/geese/seqe/wpcontent/uploads/2010/11/Apostila.pdf>. Acesso em: 06 maio 2019.

SORGATO, Márcio José. A influência do comportamento do usuário no desempenho térmico e energético de edificações residenciais. 2015. Tese (Doutorado) Curso de Pós Graduação em Engenharia Civil, Universidade Federal de Santa Catarina, Florianópolis. Disponível em: <https:/ / repositorio.ufsc.br/bitstream/ handle/123456789/169395/338876.pdf?sequence=1\&isAllowed=y >. Acesso em: 05 maio 2019.

VENTURA, Magda Maria. O estudo de caso como modalidade de pesquisa. Revista SOCERJ, Rio de Janeiro, 20(5), p.383-386, 2007. 